\title{
Oral Mucositis and Stomatitis Associated with Conventional and Targeted Anticancer Therapy
}

\author{
Amy L Parkhill* \\ St. John Fisher College, Wegmans School of Pharmacy, Rochester, NY, USA
}

\begin{abstract}
Oral mucositis and stomatitis are characterized by pain, inflammation, and redness in the oral cavity. In the case of mucositis, ulceration also occurs. Despite being understudied, these symptoms are some of the most troubling, and yet common, adverse effects associated with cancer treatment. The incidence of these toxicities is highly variable depending on treatment-related and patient-related risk factors. However, most cancer treatment regimens carry some risk of this toxicity. The presence of mucositis or stomatitis can result in a significant decrease in the patient's quality of life due to severe pain and the inability to eat or drink. These toxicities can also negatively affect the overall outcome of cancer treatment, leading to dose reductions and delays in treatment. Although the mechanism is not yet understood, the rapid increase in the number of targeted anticancer therapies available on the market has increased the number of patients who experience oral toxicities. The toxicities caused by targeted agents are less severe than those caused by conventional anticancer agents, but due to prolonged dosing schedules, they can still lead to significant declines in quality of life. The pathobiology of oral mucositis is a complex five phase process. It involves injury, activation of enzymes and transcription factors, upregulation of cytokine genes, inflammation/damage to tissue, and healing. These processes not only involve cells in the oral mucosa, but also the surrounding fibroblasts and connective tissue cells. A better understanding of the mechanisms behind oral mucositis and stomatitis will facilitate the development of effective prediction, prevention, and treatment strategies.
\end{abstract}

Keywords: Oral mucositis; Stomatitis; Oral toxicities; Chemotherapy; Targeted cancer therapy

\section{Introduction}

It is indisputable that the effective treatment of malignancies is often limited by the harm inflicted on normal, healthy cells [1]. Given their high rate of turnover, mucosal cells in the oral cavity are highly susceptible to the toxic effects of cancer treatment [2]. Toxicities of the oral cavity, which include mucositis and stomatitis, are some of the most significant and unavoidable toxicities associated with cancer treatment [3]. Advances in the ability of anticancer treatment to damage and kill cancer cells has also led to changes in the incidence, nature, and severity of oral complications [3]. Cytotoxic chemotherapy has long been associated with a high risk of oral toxicity. However, the risk associated with the newer targeted agents is only begun to be realized. Despite being underreported and often under recognized, oral toxicities have a tremendous impact on the cancer patient and on the resources of the healthcare system. For example, oral toxicities are a common cause of dose delays and interruptions of cancer therapy [4]. Unfortunately, the currently available treatments for oral toxicities are primarily palliative and in many cases, only marginally effective [57]. The lack of effective treatments and prevention strategies may be attributed to the fact that research on oral toxicities has lagged behind research on other chemotherapy and radiation-related toxicities such as febrile neutropenia and nausea and vomiting [4].

\section{Mucositis and Stomatitis}

The damage inflicted upon the oral cavity by various modalities of cancer treatment can result in a variety of conditions including

\begin{tabular}{|l|c|}
\hline Grade 1 & Oral soreness, erythema \\
\hline Grade 2 & Ulcers, but able to eat solid food \\
\hline Grade 3 & Oral ulcers and able to take liquids only \\
\hline Grade 4 & Oral alimentation impossible \\
\hline
\end{tabular}

Table 1: World Health Organization Oral Mucositis Scale adapted from $[4,10]$ oral mucositis and stomatitis. Clinically, the terms mucositis and stomatitis are often used interchangeably, but they do not have identical pathologies [2].

Mucositis is the term describing the lesions caused by anticancer agents. It can occur to any mucosal cells, but most commonly occurs in the cells of the oral cavity and small intestine [5]. Oral mucositis caused by cytotoxic chemotherapy is characterized by painful inflammation, erythema, swelling, and ulcerations of the oral mucosa in the oral cavity, oropharynx, and hypopharynx [8,9]. Oral mucositis varies in intensity from a grade 1 to a grade 4 . Grade 1 is characterized by redness and soreness and grade 4 prevents the patient from ingesting anything orally (Table 1) [10].

Stomatitis refers to inflammation that occurs in any tissue in the oral cavity [9]. Therefore, stomatitis includes a broad range of conditions, including oral mucositis. A majority of the research performed to date has specifically focused on oral mucositis. However, the increasing use of targeted anticancer agents (e.g. mammalian target of rapamycin (mTOR) inhibitors, inhibitors of Epidermal Growth Factor Receptor (EGFR) signaling, and tyrosine kinase inhibitors) has brought forth the need to carefully distinguish between the pathology and pathogenesis of mucositis and stomatitis.

*Corresponding author: Amy L Parkhill, St. John Fisher College, Wegmans School of Pharmacy, Rochester, NY USA, Tel: (585) 385-7235; Fax: (585) 3855295; E-mail: aparkhill@sjfc.edu

Received June 10, 2013; Accepted August 27, 2013; Published September 11, 2013

Citation: Parkhill AL (2013) Oral Mucositis and Stomatitis Associated with Conventional and Targeted Anticancer Therapy. J Pharmacovigilance 1: 112. doi:10.4172/23296887.1000112

Copyright: @ 2013 Parkhill AL. This is an open-access article distributed under the terms of the Creative Commons Attribution License, which permits unrestricted use, distribution, and reproduction in any medium, provided the original author and source are credited. 


\begin{tabular}{|l|l|}
\hline \multicolumn{1}{|c|}{ Treatment-related } & \multicolumn{1}{c|}{ Patient-related } \\
\hline - Type of medication & - Type of malignancy \\
\hline - Dose & - Age \\
\hline $\begin{array}{l}\text { - Schedule of medication (e.g. } \\
\text { number of cycles) }\end{array}$ & - Poor oral health and hygiene \\
\hline - Route of administration & - Salivary gland dysfunction \\
\hline - Concomitant radiation therapy & - Body mass index \\
\hline - Dose and field of radiation & - Gender \\
\hline & - Genetic polymorphisms in drug \\
& metabolizing enzymes[22]and TNF- $\alpha$ [21] \\
\hline & - Co-morbid disease states (e.g. psoriasis, \\
& Addison's disease, diabetes) [6] \\
\hline
\end{tabular}

Table 2: Risk factors for oral mucositis adapted from $[9,20]$.

\section{Epidemiology of Oral Mucositis}

The incidence and severity of mucositis is highly variable and is dependent on treatment-related and patient-related risk factors [11] (Table 2). Currently, treatment-related risk factors are more important to consider than patient-related factors, and should be assessed before treatment initiation [4]. Treatment-related risk factors include type, dose, schedule of chemotherapy, route of administration, and concomitant use of chemotherapy and radiation $[9,12]$. Patients who receive standard-dose chemotherapy has an estimated $40 \%$ risk of all-grade mucositis [13] and the risk of mucositis approaches 100\% in patients with head and neck cancer who receive both intensive chemotherapy and radiation $[4,14]$. The overall risk of developing mucositis and the severity of mucositis positively correlate with the number of chemotherapy cycles due to increased exposure and the cumulative damage caused by anticancer agents $[3,4]$.

The reported incidence of mucositis is striking. However, it is likely what the true incidence of mucositis in clinical practice is much higher. Currently available knowledge on oral mucositis is derived from clinical trials. Unfortunately, relatively few clinical trials have focused on mucositis as a specific outcome and clinical trials often do not include the full range of patients (e.g. elderly patients, patients with comorbidities, non-adherent patients) [4]. Additionally, mucositis often emerges between treatment cycles when clinical monitoring is sporadic [15].

Although it is difficult to predict whether a patient will develop mucositis solely based on the class of drug dispensed [2], there are several drugs that are associated with an increased propensity to damage the oral mucosa. These drugs include methotrexate, doxorubicin, 5-fluorouracil, busulfan, bleomycin, cisplatin, carboplatin, mTOR inhibitors, inhibitors of EGFR signaling, and selected tyrosine kinase inhibitors [2,4,8,16-19].

Most research has focused on treatment-related risk factors, given the variable response of individual patients to the same treatment regimen. However, patient-related risk factors also play an important role in oral toxicity risk [4]. Currently, data is inconclusive pertaining to the influence of age, gender, body mass index, and nutritional status on chemotherapy-induced mucositis $[4,20]$. However, the impact of genetic factors has become unmistakable. Importantly, differences in the expression of genes associated with the pathogenesis of mucositis are common [9]. For example, polymorphisms in the tumor necrosis factor genes have been shown to increase the risk of toxic lesions [21]. Additionally, although relatively rare, deficiencies in drug metabolizing enzymes due to genetic polymorphisms have been associated with an increased risk of methotrexate-induced and 5-fluorouracil-induced toxicity [22-24]

\section{Impact on Patients}

As reported by patients, mucositis is one of the most significant adverse symptoms of cancer therapy $[25,26]$. Resources that are needed to manage the acute effects of mucositis and its impact on the patient include, but are not limited to: total parental nutrition, increased use of antifungals and opioid analgesics, increased emergency department visits, and increased hospitalizations $[4,27,28]$. The substantial pain and ulceration can lead to a decline in oral health, nutritional status, quality of life, and in severe cases, even death [27,29-31]. The pain associated with mucositis can persist after treatment is complete and its management may require parenteral opioid analgesics [32,33]. Unfortunately, opioid analgesics are not always effective in managing the pain and are associated with aversive side effects such as constipation and a decrease in alertness $[9,25,27]$. The pain can also interfere with the patient's ability to eat and drink which can lead to weight loss in already frail patients and required initiation of total parenteral nutrition [26].

The ulcerations in mucositis can create a portal of entry for pathogens in a patient that may already be immunocompromised due to myelosuppression [4]. In severe cases, this can lead to life-threatening systemic infections [34,35]. Research has shown that infection occurs in $36 \%$ of solid tumor patients receiving myelosuppressive therapy. However, in patients who experience mucositis due to myelosuppressive therapy, the occurrence of infection increases to $73 \%$ [15]. Unfortunately, these infections may be hard to prevent and predict because there are no specific criteria for determining risk of infection during myelosuppression [2].

Mucositis can be considered a dose-limiting toxicity. A reduction or delay in treatment may be warranted given complications associated with pain, infection, and inability to eat. As reviewed by Elting et al. [28], mucositis can lead to a dose reduction of chemotherapy in $23 \%$ $28 \%$ of cycles. These dose reductions are a major source of concern because they can directly diminish cure rates and patient survival [5].

\section{Pathobiology of Mucositis}

The emergence of oral mucositis after intensive chemotherapy occurs approximately two weeks after chemotherapy initiation [36], which corresponds to the estimated mitotic rate of oral epithelium of 9 to 16 days [37]. It was previously thought that mucosal toxicity was simply due to the direct toxicity of chemotherapy agents on mucosal cells [38]. However, research has determined that the development of mucositis involves not only the mucosal epithelium, but the submucosa and the extracellular matrix [39]. The pathobiology follows a discrete five phase process that includes: 1. Initiation, 2. Signaling, 3. Amplification, 4. Ulceration, and 5. Healing [6,39] (Table 3). An important implication of this model is that it identifies a variety of potential therapeutic

\begin{tabular}{|c|c|}
\hline $\begin{array}{l}\text { Phase I- } \\
\text { Initiation }\end{array}$ & $\begin{array}{l}\text { Exposure to chemotherapy or radiation causes generation of } \\
\text { reactive oxygen species (ROS) and lipid peroxidation. This results } \\
\text { in DNA damage and cellular apoptosis }\end{array}$ \\
\hline $\begin{array}{l}\text { Phase II - } \\
\text { Signaling }\end{array}$ & $\begin{array}{l}\text { ROS cause further damage and stimulate the expression of } \\
\text { NF- } \kappa \text { B. NF- } \kappa \text { B expression leads to increased production of } \\
\text { proinflammatory cytokines (TNF- } \alpha, I L-1 \beta, I L-6)\end{array}$ \\
\hline $\begin{array}{l}\text { Phase III - } \\
\text { Amplification }\end{array}$ & $\begin{array}{l}\text { Release of proinflammatory cytokines leads to prolonged } \\
\text { tissue injury, apoptosis, vascular permeability, and activation of } \\
\text { cyclooxygenase- } 2 \text {. }\end{array}$ \\
\hline $\begin{array}{l}\text { Phase IV - } \\
\text { Ulceration }\end{array}$ & $\begin{array}{l}\text { Ulceration occurs, providing a portal for the entry for colonization } \\
\text { of microorganisms. Bacteria cause activation of macrophages and } \\
\text { further production of proinflammatory cytokines }\end{array}$ \\
\hline $\begin{array}{l}\text { Phase V - } \\
\text { Healing }\end{array}$ & $\begin{array}{l}\text { Signals from submucosa promote epithelial proliferation and } \\
\text { differentiation }\end{array}$ \\
\hline
\end{tabular}

Table 3: The phases of oral mucositis adapted from [6,39]. 
targets (e.g. sequesters of free radicals, inhibitors of pro-inflammatory cytokines) that could hinder or reverse the development of mucositis.

Another interesting aspect of the model is that it demonstrates that microorganisms are a coincident condition and not a direct cause of mucositis [6]. In a hamster model of mucositis, the development of lesions preceded increases in bacterial colonization [6]. Even though microorganisms may not directly cause mucositis, it is important to note that the presence of infection can often complicate the diagnosis and management of oral mucositis [40].

\section{Oral Toxicity Caused by Targeted Anticancer Therapy}

The use of targeted agents in the treatment of cancer has recently exploded and has had a significant positive impact on patient quality of life and survival rates [1]. Since 2012, 14 agents have been approved by the U.S. Food and Drug Administration [41]. These agents influence or inhibit the signaling of many cellular targets including mTOR, EGFR, vascular endothelial growth factor, hedgehog, human epidermal growth factor receptor 2 , and several tyrosine kinases. This explosion of targeted agents represents the products of the extensive research that has occurred in the field of cancer cell biology. However, the presence and function of some of these targets in normal cells is just beginning to be understood. Unfortunately therefore, targeted anticancer therapy can also cause significant toxicity to non-cancer cells.

Mucositis is one of the most commonly reported toxicities of mTOR inhibitors $[42,43]$, and in some studies, it was the dose-limiting toxicity [44]. Oral toxicities with other targeted agents, such as the kinase inhibitors and monoclonal antibodies are less common. Yet studies have shown a significant incidence of all-grade mucositis with bevacizumab, erlotinib, sorafenib, and sunitinib [15,43]. The incidence of oral toxicity associated with targeted agents has been shown to increase as the dose increases [45]. However, unlike with the conventional anticancer agents, subsequent cycles of targeted agent therapy can lead to a decrease in the frequency and severity of oral toxicity [45].

The clinical presentation of targeted agent-induced oral mucositis is quite different from radiation or chemotherapy-induced mucositis. Typically, it has a rapid onset (within 5 days) and is of mild to moderate severity (grade 1-2). The lesions are round and have similar appearance to aphthous stomatitis (canker sores) $[12,46]$. Another distinguishing feature of targeted therapy-induced oral toxicity is that the lesions are more likely to resolve spontaneously even when treatment is continued [42]. Given these differences, the toxicities seen with targeted agents may be better classified as stomatitis, rather than oral mucositis $[12,40,47]$

Although the severity of targeted agent-induced oral toxicity is less severe than that caused by conventional chemotherapy, it may still be dose-limiting $[12,17,19]$. Treatment with targeted agents is often longterm and may continue until the cancer has progressed or unacceptable toxicity occurs. Because many of the targeted agents are taken orally and are self-administered, the negative impact of targeted therapyinduced oral toxicities on patient adherence and treatment outcomes is significant $[17,48]$.

The exact mechanism of how targeted agents produce oral toxicities is likely different than the pathways described for conventional chemotherapy agents. Recent research done in a clinically relevant rat model of tyrosine kinase inhibitor-induced diarrhea has identified that unlike with conventional chemotherapy agents, tyrosine kinase inhibitors do not cause direct damage to mucosal cells [49]. However, apart from that, the targeted agent-induced mechanism is not well- understood. This may be due in part because targeted agents are often given in conjunction or after conventional anticancer therapies have been given. Therefore, the toxicities of targeted agents can combine with or accentuate the toxicities of conventional chemotherapy and it may be difficult to distinguish toxicities solely caused by the targeted agent.

\section{Future Directions}

Recent years have seen an increase in the amount and the momentum surrounding mucositis research in both clinics and in laboratories. Unfortunately, anticancer agents are not currently classified based on their oral mucositis risk [4]. Therefore, strategies for prevention and treatment are still limited and the majority of currently available studies have significant weaknesses [9]. For example, there are few studies that focus on chronic complications and survivorship issues [8]. However, as cancer survivor rates increase, it becomes important to understand the impact of mucositis on the long-term oral health and well-being of the patient [3]. Additionally, given the impact that oral toxicities have on daily functioning, there is a need for research to focus not only on the incidence of oral mucositis and stomatitis, but also on the severity and duration. In order to accomplish this, studies would likely need to increase monitoring between treatment cycles and also incorporate patient-reported symptoms with clinical diagnostic tools [15]

The discovery of the complex pathobiology of mucositis has undeniably created several potential avenues for drug development and research [6]. However, given the complexity of most cancer treatment regimens, it will be challenging to manage the toxicities of simultaneous multiple agents, some of which have an unknown mechanism, without jeopardizing the ultimate goal of destroying cancer cells [50]. For example, it is possible that the desired treatment effect and the undesired toxicity are inseparable and that attenuating toxicity will also lead to reductions in efficacy [51].

\section{Conclusion}

As Sonis states, mucositis is toxicity that "largely defies effective intervention" $[12,50]$. Now that febrile neutropenia and chemotherapyinduced nausea and vomiting are managed with various pharmacologic agents, mucositis has become one of the most troubling dose-limiting toxicities for patients. However, given the tremendous impact that these oral toxicities have on the patient and the healthcare system, urgent studies are needed to develop effective strategies for prevention and treatment.

\section{References}

1. Keefe DM, Bateman EH (2011) Tumor control versus adverse events with targeted anticancer therapies. Nat Rev Clin Oncol 9: 98-109.

2. National Cancer Institute (2013) Oral Complications of Chemotherapy and Head/Neck Radiation PDQ®.

3. Epstein JB, Thariat J, Bensadoun RJ, Barasch A, Murphy BA, et al. (2012) Oral complications of cancer and cancer therapy: from cancer treatment to survivorship. CA Cancer J Clin 62: 400-422.

4. Bensinger W, Schubert M, Ang KK, Brizel D, Brown E, et al. (2008) NCCN Task Force Report. prevention and management of mucositis in cancer care. J Natl Compr Canc Netw 6 Suppl 1: S1-21.

5. Keefe DM, Sonis ST, Bowen JM (2008) Emerging drugs for chemotherapyinduced mucositis. Expert Opin Emerg Drugs 13: 511-522.

6. Sonis ST (2009) Mucositis: The impact, biology and therapeutic opportunities of oral mucositis. Oral Oncol 45: 1015-1020.

7. Al-Azri AR, Gibson RJ, Keefe DM, Logan RM (2013) Matrix metalloproteinases: do they play a role in mucosal pathology of the oral cavity? Oral Dis 19: 347 359 . 
Citation: Parkhill AL (2013) Oral Mucositis and Stomatitis Associated with Conventional and Targeted Anticancer Therapy. J Pharmacovigilance 1: 112. doi:10.4172/2329-6887.1000112

Page 4 of 4

8. Watters AL, Epstein JB, Agulnik M (2011) Oral complications of targeted cancer therapies: a narrative literature review. Oral Oncol 47: 441-448.

9. Raber-Durlacher JE, Elad S, Barasch A (2010) Oral mucositis. Oral Oncol 46: $452-456$

10. WHO (1979) WHO Handbook for Reporting Results for Cancer Treatment Geneva.

11. Barasch A, Peterson DE (2003) Risk factors for ulcerative oral mucositis in cancer patients: unanswered questions. Oral Oncol 39: 91-100.

12. Sonis S, Treister N, Chawla S, Demetri G, Haluska F (2010) Preliminary characterization of oral lesions associated with inhibitors of mammalian target of rapamycin in cancer patients. Cancer 116: 210-215.

13. Naidu MU, Ramana GV, Rani PU, Mohan IK, Suman A, et al. (2004) Chemotherapy-induced and/or radiation therapy-induced oral mucositiscomplicating the treatment of cancer. Neoplasia 6: 423-431.

14. Trotti A, Bellm LA, Epstein JB, Frame D, Fuchs HJ, et al. (2003) Mucositis incidence, severity and associated outcomes in patients with head and neck cancer receiving radiotherapy with or without chemotherapy: a systematic literature review. Radiother Oncol 66: 253-262.

15. Elting LS, Chang YC, Parelkar P, Boers-Doets CB, Michelet M, et al. (2013) Risk of oral and gastrointestinal mucosal injury among patients receiving selected targeted agents: a meta-analysis. Support Care Cancer

16. Keefe DM, Schubert MM, Elting LS, Sonis ST, Epstein JB, et al. (2007) Updated clinical practice guidelines for the prevention and treatment of mucositis. Cancer 109: 820-831.

17. Boers-Doets CB, Epstein JB, Raber-Durlacher JE, Ouwerkerk J, Logan RM, e al. (2012) Oral adverse events associated with tyrosine kinase and mammalian target of rapamycin inhibitors in renal cell carcinoma: a structured literature review. Oncologist 17: 135-144.

18. Martins F, de Oliveira MA, Wang Q, Sonis S, Gallottini M, et al. (2013) A review of oral toxicity associated with mTOR inhibitor therapy in cancer patients. Oral Oncol 49: 293-298.

19. de Oliveira MA, Martins E Martins F, Wang Q, Sonis S, Demetri G, et al. (2011) Clinical presentation and management of mTOR inhibitor-associated stomatitis. Oral Oncol 47: 998-1003.

20. Pico JL, Avila-Garavito A, Naccache P (1998) Mucositis: Its Occurrence, Consequences, and Treatment in the Oncology Setting. Oncologist 3: 446-451.

21. Bogunia-Kubik K, Polak M, Lange $A$ (2003) TNF polymorphisms are associated with toxic but not with aGVHD complications in the recipients of allogeneic sibling haematopoietic stem cell transplantation. Bone Marrow Transplant 32 617-622.

22. Robien K, Schubert MM, Bruemmer B, Lloid ME, Potter JD, et al. (2004) Predictors of oral mucositis in patients receiving hematopoietic cell transplants for chronic myelogenous leukemia. J Clin Oncol 22: 1268-1275.

23. Sloan JA, Goldberg RM, Sargent DJ, Vargas-Chanes D, Nair S, et al. (2002) Women experience greater toxicity with fluorouracil-based chemotherapy for colorectal cancer. J Clin Oncol 20: 1491-1498.

24. Schwab M, Zanger UM, Marx C, Schaeffeler E, Klein K, et al. (2008) Role of genetic and nongenetic factors for fluorouracil treatment-related severe toxicity: a prospective clinical trial by the German 5-FU Toxicity Study Group. J Clin Oncol 26: 2131-2138

25. Bellm LA, Epstein JB, Rose-Ped A, Martin P, Fuchs HJ (2000) Patient reports of complications of bone marrow transplantation. Support Care Cancer 8: 33-39.

26. Rose-Ped AM, Bellm LA, Epstein JB, Trotti A, Gwede C, et al. (2002) Complications of radiation therapy for head and neck cancers. The patient's perspective. Cancer Nurs 25: 461-467.

27. Elting LS, Keefe DM, Sonis ST, Garden AS, Spijkervet FK, et al. (2008) Patientreported measurements of oral mucositis in head and neck cancer patients treated with radiotherapy with or without chemotherapy: demonstration of increased frequency, severity, resistance to palliation, and impact on quality of life. Cancer, 113: 2704-2713.

28. Elting LS, Cooksley C, Chambers M, Cantor SB, Manzullo E, et al. (2003) The burdens of cancer therapy. Clinical and economic outcomes of chemotherapyinduced mucositis. Cancer 98: 1531-1539.

29. Stiff $P$ (2001) Mucositis associated with stem cell transplantation: current status and innovative approaches to management. Bone Marrow Transplant 27 Suppl 2: S3-3S11.

30. Duncan GG, Epstein JB, Tu D, El Sayed S, Bezjak A, et al. (2005) Quality of life, mucositis, and xerostomia from radiotherapy for head and neck cancers: a report from the NCIC CTG HN2 randomized trial of an antimicrobial lozenge to prevent mucositis. Head Neck 27: 421-428.

31. Lalla RV, Peterson DE (2005) Oral mucositis. Dent Clin North Am 49: 167-184, ix.

32. Miaskowski C (2001) Biology of mucosal pain. J Natl Cancer Inst Monogr : $37-40$

33. Cella D, Pulliam J, Fuchs H, Miller C, Hurd D, et al. (2003) Evaluation of pain associated with oral mucositis during the acute period after administration of high-dose chemotherapy. Cancer 98: 406-412.

34. Rapoport AP, Miller Watelet LF, Linder T, Eberly S, Raubertas RF, et al. (1999) Analysis of factors that correlate with mucositis in recipients of autologous and allogeneic stem-cell transplants. J Clin Oncol 17: 2446-2453.

35. Ruescher TJ, Sodeifi A, Scrivani SJ, Kaban LB, Sonis ST (1998) The impact of mucositis on alpha-hemolytic streptococcal infection in patients undergoing autologous bone marrow transplantation for hematologic malignancies. Cancer 82: $2275-2281$.

36. Sonis ST (1998) Mucositis as a biological process: a new hypothesis for the development of chemotherapy-induced stomatotoxicity. Oral Oncol 34: 39-43.

37. Squier CA (1990) Oral complications of cancer therapies. Mucosal alterations $\mathrm{NCl}$ Monogr : 169-172.

38. Sonis ST, Lindquist L, Van Vugt A, Stewart AA, Stam K, et al. (1994) Prevention of chemotherapy-induced ulcerative mucositis by transforming growth factor beta 3. Cancer Res 54: 1135-1138.

39. Sonis ST (2004) The pathobiology of mucositis. Nat Rev Cancer 4: 277-284

40. Lalla RV, Sonis ST, Peterson DE (2008) Management of oral mucositis in patients who have cancer. Dent Clin North Am 52: 61-77, viii.

41. Cancer Watch (2012) FDA approved drugs. FDA, USA

42. Sankhala K, Mita A, Kelly K, Mahalingam D, Giles F, et al (2009) The emerging safety profile of mTOR inhibitors, a novel class of anticancer agents. Target Oncol 4: 135-142.

43. Li E, Trovato JA (2012) New developments in management of oral mucositis in patients with head and neck cancer or receiving targeted anticancer therapies. Am J Health Syst Pharm 69: 1031-1037.

44. O'Donnell A, Faivre S, Burris HA 3rd, Rea D, Papadimitrakopoulou V, et al. (2008) Phase I pharmacokinetic and pharmacodynamic study of the ora mammalian target of rapamycin inhibitor everolimus in patients with advanced solid tumors. J Clin Oncol 26: 1588-1595.

45. Mita MM, Mita AC, Chu QS, Rowinsky EK, Fetterly GJ, et al. (2008) Phase I tria of the novel mammalian target of rapamycin inhibitor deforolimus (AP23573 MK-8669) administered intravenously daily for 5 days every 2 weeks to patients with advanced malignancies. J Clin Oncol 26: 361-367.

46. Messadi DV, Younai F (2010) Aphthous ulcers. Dermatol Ther 23: 281-290.

47. Al-Dasooqi N, Sonis ST, Bowen JM, Bateman E, Blijlevens N, et al. (2013) Emerging evidence on the pathobiology of mucositis. Support Care Cancer.

48. Harris DJ, Eilers J, Harriman A, Cashavelly BJ, Maxwell C (2008) Putting evidence into practice: evidence-based interventions for the management of oral mucositis. Clin J Oncol Nurs 12: 141-152.

49. Bowen JM, Mayo BJ, Plews E, Bateman E, Stringer AM, et al (2012) Development of a rat model of oral small molecule receptor tyrosine kinase inhibitor-induced diarrhea. Cancer Biol Ther 13: 1269-1275

50. Sonis S (2011) The quest for effective treatments of mucositis. J Support Onco 9: $170-171$.

51. Keefe DM (2007) Supportive care silos: time to forge cross-links, using mucositis as an example. Curr Opin Support Palliat Care 1: 40-42.

This article was originally published in a special issue, Patterns of Adverse Drug Reactions for Cancer Drugs handled by Editor(s). Dr. Lipika Chablani, Wegmans School of Pharmacy, St. John Fisher College, United States 